\title{
Reliability and validity of the KIDSCREEN-52 health-related quality of life questionnaire in a Greek adolescent population
}

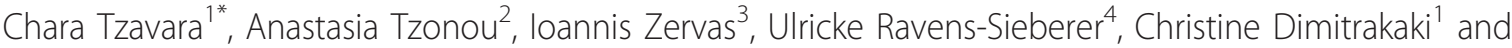 \\ Yannis Tountas ${ }^{1}$
}

\begin{abstract}
Background: The KIDSCREEN-52 is a worldwide instrument for measuring health-related quality of life (HRQoL) in children and adolescents. The aim of this study is to assess reliability and validity of the Greek version of KIDSCREEN.

Methods: Questionnaires were collected from a representative nationwide sample of 1,194 adolescents aged from 11 to 17 years. Internal consistency reliability was determined by calculation of the Cronbach $\alpha$ coefficient. A confirmatory factor analysis (CFA) was conducted in order to test the construct validity of the questionnaire. Validity was further examined by investigating the correlation of KIDSCREEN with the Strengths and Difficulties Questionnaire (SDQ) and its association with socioeconomic and health-related factors.

Results: Internal consistency reliability was accepted with a Cronbach $\alpha$ above 0.73 for all KIDSCREEN dimensions. CFA showed that the ten-dimensional model fitted the data well (root mean square error of approximation $($ RMSEA $)=0.048$, comparative fit index $(C F I)=0.971$ and goodness of fit index $(G F I)=0.965)$. Correlation coefficients between KIDSCREEN and SDQ dimensions were significant. Adolescents of low socioeconomic status reported lower scores in the majority of KIDSCREEN dimensions. Also, adolescents with chronic health problem had poorer quality of life concerning physical well-being and other dimensions of KIDSCREEN.
\end{abstract}

Conclusions: The Greek version of KIDSCREEN-52 was found to have satisfied psychometric properties and could be suitable for assessing HRQOL in Greek adolescents.

Keywords: adolescents, health-related quality of life, measurement, questionnaire, validity

\section{Background}

Health-related quality of life (HRQoL) is conceptualized as a multidimensional and comprehensive model of health with several domains. This flows from the definition of health put forward by the World Health Organization (WHO) as a state of complete physical, emotional and social well-being, associated with the individual's perception of their position in life and not the absence of illness [1]. The assessment of HRQoL plays an important role in the assessment of adult health, as indicated by the development of many generic

\footnotetext{
* Correspondence: htzavara@med.uoa.gr

'Centre for Health Services Research, Department of Hygiene, Epidemiology and Medical Statistics, Athens University Medical School, Athens, Greece Full list of author information is available at the end of the article
}

measurement instruments in recent years [2]. The measurement of HRQoL in children and adolescents has received increasing attention in pediatrics and adolescent care and several instruments are now available for use in these groups [3]. Changes in emotional and cognitive development in children and adolescents must be recognized and addressed [4]. Recently, studies have shown that children and adolescents are able to answer the HRQoL questionnaires reliably if their emotional development, cognitive capacity, and reading skills are taken into account [5]. Generic HRQoL instruments can be useful in the identification of groups with health problems or disabilities [6]. Monitoring HRQoL in children and adolescents can also be useful for the evaluation of health services. From an edidemiological perspective it 
is desirable to have valid HRQoL instruments to aid with public policy decisions and public health promotion strategies and consequently the improvement of population health [6].

The KIDSCREEN-52 52-item questionnaire was funded by the European Commission and measures health-related quality of life of children and adolescents aged 8 to 18 years. The generic KIDSCREEN-52 HRQoL questionnaire is the first instrument for children and adolescents that was developed in several different countries and tested in a large representative sample of children and adolescents [4], thereby helping to provide a broad perspective on the understanding and interpretation of HRQoL across different countries. Psychometric properties such as validity and reliability of the KIDSCREEN-52 HRQoL questionnaire have been assessed in previous studies [7-11] and its crosscultural comparability and psychometric properties have been found satisfactory. The aim of the present study was to assess the reliability and construct validity of the KIDSCREEN-52 quality of life measure in a Greek adolescent population. More specifically, the aim was to examine internal consistency reliability and construct validity by confirmatory factor analysis (CFA) and by the correlation of KIDSCREEN-52 with the scales of the Strengths and Difficulties Questionnaire (SDQ), which investigates emotional and behavioral problems [12]. Also, comparisons according to socioeconomic status and the existence of chronic disease are discussed.

\section{Methods \\ Participants and procedure}

The study was conducted during the year 2003 in Greece within the framework of the European project 'Screening and Promotion for HRQoL in Children and Adolescents - A European Public Health Perspective' [4]. The sampling was random, multistaged and based on the age and sex distribution of school-age children living in the 54 geographical sectors of the country, according to data from the National Census of 2001. A sample of 1,900 adolescents (11 to 18 year olds) was recruited. Adolescents filled in the questionnaire at school. A total of 1,194 (that is, $63 \%$ response rate) of self-reported questionnaires $(40.07 \%$ boys $)$ were returned. Inclusion criteria for the adolescents were to be between 11 and 18 years old, to be able to read and complete the questionnaires themselves, and to consent to be involved in the study. Ethical approval was attained from the National Ministry of Education. Previous research on the representativeness of the present sample has reported that non-responder interviews showed no significant differences between responders and non-responders with regard to the general perceived health of adolescents and parents, the marital status of parents, highest educational level, and type of residence, indicating that a selection bias is unlikely [13].

\section{Measures}

The KIDSCREEN-52 questionnaire consists of 52 items and is based on a multidimensional HRQoL construct. The questionnaire was translated from English into Greek according to international guidelines using a backward-forward translation technique and international harmonization sessions $[14,15]$. The instrument assesses either the frequency of behavior/feelings or intensity of an attitude using a five-point Likert scale (1 = never, $2=$ seldom, $3=$ sometimes, $4=$ often, $5=$ always) and the recall period is 1 week. The questionnaire is categorized into ten dimensions: physical wellbeing, psychological well-being, moods and emotions, self-perception, autonomy, parent relation and home life, peers and social support, school environment, social acceptance (bullying) and financial resources. The score for each dimension was transformed to a 0 to 100 point scale with higher scores indicate better HRQoL.

The SDQ questionnaire contains 25 items, categorized into 5 scales of 5 items each: hyperactivity/inattention, emotional symptoms, conduct problems, peer problems and prosocial behavior [12]. Responses to each of the 25 items consisted of 3 options: not true, somewhat true, or certainly true. The version for youths was used in the present study, which was found to have satisfactory psychometric properties in Greek adolescents [16].

To assess familial socioeconomic status, the Family Affluence Scale (FAS) was used [17], addressing issues of family car ownership, children having their own unshared room, the number of computers at home and time the adolescents spent on holiday in the past 12 months. The FAS was collected from adolescents in seven categories (from 0 the lowest, to 7 the highest FAS category) and was recoded into three groups in the analysis (low FAS level (0 to 3 ), intermediate (4 to 5 ) and high FAS level (6 to 7)). The psychometric properties of the FAS are acceptable and support its use as a self-reported measure for adolescents $[18,19]$. Low FAS was expected to be associated with lower scores on KIDSCREEN-52 dimensions, but especially for financial resources.

To assess special chronic healthcare needs, the Children with Special Health Care Needs Screener (CSHCN) was included in the questionnaire, as a measure of physical and emotional chronic health status in children $[20,21]$. The CSHCN contains five question sequences: each question is followed by two additional questions, asking about the presence and duration of any health conditions. The five questions address the use or need of prescription medication; the use or need of medical, mental health or educational services; functional 
limitations; use and need of specialized therapies (occupational therapy, physiotherapy, speech therapy, and so on); and treatment or counseling for emotional or developmental problems, all associated with a health problem that has lasted or is expected to last 12 months or longer. It was expected that adolescents with a chronic health condition would have lower scores of HRQoL, especially for the dimension of Physical Well-Being [3].

\section{Statistical analysis}

A confirmatory factor analysis (CFA) with maximum likelihood procedure was conducted in order to test how well the ten-dimension KIDSCREEN-52 model fits the data. The variance of the latent constructs was fixed at 1 during parameter estimation and the factors were allowed to be correlated. The fit of the CFA model was assessed using the $\chi^{2}$ test, the comparative fit index (CFI), the goodness of fit index (GFI) and the root mean square error of approximation (RMSEA) [22]. For the CFI and GFI indices, values close to or greater than 0.95 are taken to reflect a good fit to the data [23]. RMSEA values of less than 0.05 indicate a good fit and values as high as 0.08 indicate a reasonable fit [23]. Also, a non-significant $\chi^{2}$ statistic indicates a good fit, but $\chi^{2}$ is usually sensitive to sample sizes and is usually significant for large sample sizes such as ours [22]. Scale internal consistency reliability was determined by calculation of the Cronbach $\alpha$ coefficient. Scales with reliabilities equal to or greater than 0.70 were considered acceptable. Validity was further examined with the correlation (Pearson's r) of KIDSCREEN-52 dimensions with SDQ scales. Correlation coefficients between 0.1 and 0.3 are considered low, between 0.31 and 0.5 moderate and over 0.5 high. Multivariate analysis of variance (MANOVA) was used in order to compare the scores of adolescents with chronic diseases with those of adolescents with no chronic diseases. Differences on KIDSCREEN-52 scales between the three socioeconomic status groups (low, middle and high) were also determined by the use of MANOVA. In order to control for multiple testing, Bonferroni correction was used. The $P$ values reported are two-tailed. The statistical significance level was set at 0.05 and analysis was conducted using SPSS and AMOS (SPSS, Chicago, IL, USA) statistical software.

\section{Results}

\section{Sample description}

The total sample included 715 adolescent girls and 478 boys $(\mathrm{N}=1,193)$. The total sample mean age was 13.6 $(\mathrm{SD}=1.7)$. A total of $50.3 \%$ of participants belonged to the aged 11 to 14 group and $49.7 \%$ belonged to the aged 15 to 17 group. A total of $37.6 \%$ were identified in the low FAS group, $45 \%$ in the medium FAS group and
$17.4 \%$ in the high FAS group. According to the CSHCN screener, $3.4 \%$ of the adolescents were suffering from a chronic health condition.

\section{Internal consistency reliability}

Cronbach $\alpha$ and mean scale scores are presented in Table 1. All the scales of KIDSCREEN-52, exceeded the minimum reliability standard of 0.70 . Cronbach $\alpha$ values ranged from 0.73 (bullying) to 0.90 (moods and emotions, social support and peers).

\section{CFA results}

As defined from the results of CFA the ten-dimensional model fitted the data well. The RMSEA, CFI and GFI values were $0.048,0.971$ and 0.965 , respectively. None of the item cross loadings exceeded the item loadings on the intended latent construct. Estimates of the tendimensional model are shown in Table 2. Factor loadings were high and ranged from 0.61 to 0.88 indicating a strong association between the latent factors and their respective items (Table 2 ). The $\chi^{2}$ test of the model was significant $\left(\chi^{2}=2,508.2, \mathrm{df}=1,299, P<0.05\right)$.

\section{Convergent and discriminant validity}

The associations of KIDSCREEN-52 dimensions with SDQ scales are shown in Table 3. Correlation analysis showed moderate to high coefficients for the expected relationships. The SDQ emotional symptoms subscale, as well as the total difficulties score correlated highest with the KIDSCREEN-52 moods and emotions dimension. Moderate correlations of the SDQ emotional subscale were also observed with the KIDSCREEN-52 dimensions of self-perception, psychological well-being, parent relation and home life, physical well-being and peers and social support. The SDQ hyperactivity subscale correlated highest with the KIDSCREEN-52 dimensions of school environment, moods and emotions and parent relation and home life. The SDQ peer problems subscale correlated highest with the

Table 1 Internal consistency and descriptive statistics of the KIDSCREEN-52 dimensions

\begin{tabular}{lccc}
\hline & Mean & SD & Cronbach $\boldsymbol{\alpha}$ \\
\hline Physical well-being & 66.1 & 19.2 & 0.83 \\
Psychological well-being & 70.0 & 19.3 & 0.88 \\
Moods and emotions & 72.6 & 18.2 & 0.90 \\
Self-perception & 66.4 & 21.0 & 0.85 \\
Autonomy & 58.7 & 23.5 & 0.81 \\
Parent relation and home life & 70.5 & 20.2 & 0.89 \\
Peers and social support & 70.4 & 21.3 & 0.90 \\
School environment & 64.2 & 18.7 & 0.88 \\
Social acceptance (bullying) & 91.9 & 14.0 & 0.73 \\
Financial resources & 69.5 & 24.3 & 0.89 \\
\hline
\end{tabular}


Table 2 Factor loadings form the results of confirmatory factor analysis of the KIDSCREEN-52 study

\begin{tabular}{|c|c|c|c|c|c|}
\hline Scale/item & b & Scale/item & b & Scale/item & $\mathbf{b}$ \\
\hline Physical well-being: & & Self-perception: & & Social support and peers: & \\
\hline How would you say your health is? & 0.70 & Have you been happy with way you are? & 0.62 & Have you spent time with your friends? & 0.62 \\
\hline Have you felt fit and well? & 0.68 & Have you been happy with your clothes? & 0.67 & Done things with other girls and boys? & 0.63 \\
\hline Been physically active? & 0.61 & Been worried about the way you look? & 0.65 & Have you had fun with your friends? & 0.67 \\
\hline Been able to run well? & 0.76 & Felt jealous of way other girls/boys look? & 0.67 & You and your friends helped each other? & 0.81 \\
\hline Felt full of energy? & 0.67 & $\begin{array}{l}\text { Like to change something about your } \\
\text { body? }\end{array}$ & 0.74 & $\begin{array}{l}\text { Able to talk about everything with } \\
\text { friends? }\end{array}$ & 0.70 \\
\hline Psychological well-being: & & Autonomy: & & $\begin{array}{l}\text { Have you been able to rely on your } \\
\text { friends? }\end{array}$ & 0.78 \\
\hline Has your life been enjoyable? & 0.65 & Have you had enough time for yourself? & 0.64 & School environment: & \\
\hline Felt pleased that you are alive? & 0.72 & $\begin{array}{l}\text { Able to do things/want to do in free } \\
\text { time? }\end{array}$ & 0.82 & Have you been happy at school? & 0.69 \\
\hline Felt satisfied with your life? & 0.75 & Had enough opportunity to be outside? & 0.82 & Have you got on well at school? & 0.61 \\
\hline Been in a good mood? & 0.79 & $\begin{array}{l}\text { Have you had enough time to meet } \\
\text { friends? }\end{array}$ & 0.72 & Been satisfied with your teachers? & 0.71 \\
\hline Felt cheerful? & 0.72 & Able to choose what to do in free time? & 0.71 & Have you been able to pay attention? & 0.64 \\
\hline Had fun? & 0.75 & Parent relation and home life: & & Have you enjoyed going to school? & 0.61 \\
\hline Moods and emotions & & Have your parent(s) understood you? & 0.71 & Got along well with your teachers? & 0.64 \\
\hline $\begin{array}{l}\text { Have you felt that you do everything } \\
\text { badly? }\end{array}$ & 0.64 & Have you felt loved by your parent(s)? & 0.72 & Social acceptance (bullying) & \\
\hline Have you felt sad? & 0.62 & Have you been happy at home? & 0.67 & Been afraid of other girls and boys? & 0.70 \\
\hline $\begin{array}{l}\text { Felt so bad that didn't want to do } \\
\text { anything? }\end{array}$ & 0.61 & Parent(s) had enough time for you? & 0.75 & $\begin{array}{l}\text { Have other girls and boys made fun of } \\
\text { you? }\end{array}$ & 0.72 \\
\hline Felt that everything in life goes wrong? & 0.73 & Have your parent(s) treated you fairly? & 0.65 & Have other girls and boys bullied you? & 0.67 \\
\hline Have you felt fed up? & 0.76 & Able to talk to parent(s) when wanted to? & 0.77 & Financial resources & \\
\hline Have you felt lonely? & 0.77 & & & Enough money to do things as friends? & 0.84 \\
\hline \multirow[t]{2}{*}{ Have you felt under pressure? } & 0.68 & & & Had enough money for your expenses? & 0.88 \\
\hline & & & & Enough money to do things with friends? & 0.86 \\
\hline
\end{tabular}

KIDSCREEN-52 dimensions of peers and social support, moods and emotions and social acceptance (bullying).

Scores of KIDSCREEN-52 dimensions by FAS categories are shown in Table 4. There were no significant differences in scores between middle and high FAS groups except for physical well-being and financial resources. All scales except for social acceptance (bullying) and autonomy differed across FAS groups and lower scores were found for those belonging to low FAS category compared to those belonging to middle or high

Table 3 Correlation coefficients of the KIDSCREEN-52 dimensions with the Strengths and Difficulties Questionnaire (SDQ)

\begin{tabular}{|c|c|c|c|c|c|c|}
\hline \multirow[t]{2}{*}{ KIDSCREEN-52 dimensions } & \multicolumn{6}{|c|}{ SDQ dimensions } \\
\hline & $\begin{array}{l}\text { Emotional } \\
\text { symptoms }\end{array}$ & $\begin{array}{l}\text { Conduct } \\
\text { problems }\end{array}$ & Hyperactivity & $\begin{array}{l}\text { Peer } \\
\text { problems }\end{array}$ & $\begin{array}{l}\text { Prosocial } \\
\text { behavior }\end{array}$ & $\begin{array}{l}\text { Total } \\
\text { difficulties }\end{array}$ \\
\hline Physical well-being & -0.33 & -0.12 & -0.23 & -0.19 & 0.16 & -0.31 \\
\hline Psychological well-being & -0.40 & -0.11 & -0.25 & -0.27 & 0.16 & -0.38 \\
\hline Moods and emotions & -0.58 & -0.23 & -0.38 & -0.35 & 0.17 & -0.56 \\
\hline Self-perception & -0.47 & -0.18 & -0.30 & -0.25 & 0.17 & -0.44 \\
\hline Autonomy & -0.28 & -0.12 & -0.12 & -0.17 & 0.13 & -0.22 \\
\hline $\begin{array}{l}\text { Parent relation and home } \\
\text { life }\end{array}$ & -0.34 & -0.23 & -0.31 & -0.23 & 0.19 & -0.38 \\
\hline Peers and social support & -0.31 & -0.16 & -0.12 & -0.40 & 0.18 & -0.30 \\
\hline School environment & -0.22 & -0.21 & -0.41 & -0.18 & 0.29 & -0.37 \\
\hline Social acceptance (bullying) & -0.26 & -0.11 & -0.16 & -0.34 & 0.19 & -0.29 \\
\hline Financial resources & -0.26 & -0.20 & -0.20 & -0.25 & 0.11 & -0.26 \\
\hline
\end{tabular}

All correlations were significant at $P<0.001$ 
Table 4 Differences in KIDSCREEN-52 dimensions according to socioeconomic status as measured by Family Affluence Scale (FAS)

\begin{tabular}{|c|c|c|c|c|c|c|c|c|c|c|}
\hline \multirow[t]{2}{*}{ Dimension } & \multicolumn{2}{|c|}{ Low FAS (A) } & \multicolumn{2}{|c|}{ Middle FAS (B) } & \multicolumn{2}{|c|}{ High FAS (C) } & \multirow[t]{2}{*}{$P$ value $^{\mathrm{a}}$} & \multicolumn{3}{|c|}{$P$ value $^{\mathrm{b}}$} \\
\hline & Mean & SD & Mean & SD & Mean & SD & & $A / B^{b}$ & $\mathrm{~A} / \mathrm{C}^{\mathrm{b}}$ & $\mathrm{B} / \mathrm{C}^{\mathrm{b}}$ \\
\hline Physical well-being & 62.8 & 19.2 & 66.7 & 18.7 & 70.6 & 18.1 & $<0.001$ & 0.004 & $<0.001$ & 0.033 \\
\hline Moods and emotions & 69.6 & 18.8 & 74.1 & 17.4 & 73.9 & 18.7 & 0.003 & 0.002 & 0.010 & 0.868 \\
\hline Self-perception & 64.1 & 21.3 & 67.1 & 20.8 & 68.5 & 21.2 & 0.020 & 0.072 & 0.007 & 0.174 \\
\hline Autonomy & 57.2 & 24.0 & 59.5 & 24.0 & 58.7 & 21.6 & 0.112 & 0.138 & 0.252 & 0.635 \\
\hline Parent relation and home life & 66.5 & 21.1 & 72.6 & 19.1 & 72.6 & 19.9 & $<0.001$ & $<0.001$ & $<0.001$ & 0.593 \\
\hline Peers and social support & 67.5 & 22.3 & 71.3 & 20.2 & 72.4 & 21.1 & 0.029 & 0.027 & 0.023 & 0.558 \\
\hline School environment & 61.5 & 19.1 & 65.7 & 18.2 & 66.4 & 18.2 & 0.007 & 0.007 & 0.009 & 0.604 \\
\hline Social acceptance (bullying) & 91.6 & 14.4 & 92.1 & 13.7 & 91.8 & 13.9 & 0.917 & 0.881 & 0.774 & 0.677 \\
\hline Financial resources & 60.1 & 25.4 & 73.4 & 21.6 & 81.1 & 19.8 & $<0.001$ & $<0.001$ & $<0.001$ & $<0.001$ \\
\hline
\end{tabular}

aultivariate analysis of variance (MANOVA).

${ }^{b}$ Post hoc analysis with Bonferroni correction for multiple comparisons.

FAS category. Scores on self-perception were significantly different only between low and high FAS categories.

Table 5 presents the mean scores of KIDSCREEN-52 dimensions for healthy adolescents and adolescents with chronic health condition. Healthy adolescents scored significantly higher on physical well-being, psychological well-being, school environment and social acceptance (bullying) dimensions.

\section{Discussion}

The KIDSCREEN-52 HRQoL questionnaire includes ten dimensions covering physical, psychological and social domains of quality of life. The main objective of the present study was to describe the psychometric properties of the Greek KIDSCREEN-52 in a sample of adolescents derived from schools. The analysis confirmed the dimension structure with sufficient psychometric properties.

Table 5 Comparison of KIDSCREEN-52 dimensions between chronically ill and healthy adolescents

\begin{tabular}{lccccc}
\hline Dimension & $\begin{array}{l}\text { Healthy } \\
\text { sample }\end{array}$ & \multicolumn{4}{c}{$\begin{array}{l}\text { Chronic } \\
\text { health }\end{array}$} \\
\cline { 2 - 5 } & Mean & SD & Mean & SD & $\boldsymbol{P}_{\text {value }}{ }^{\mathbf{a}}$ \\
\hline Physical well-being & 66.2 & 19.0 & 58.8 & 23.2 & 0.015 \\
Psychological well-being & 74.4 & 19.3 & 66.8 & 19.7 & 0.025 \\
Moods and emotions & 72.5 & 18.5 & 71.7 & 16.5 & 0.604 \\
Self-perception & 66.5 & 21.1 & 62.7 & 19.8 & 0.440 \\
Autonomy & 63.6 & 23.4 & 58.1 & 23.7 & 0.371 \\
Parent relation and home life & 70.3 & 20.0 & 67.4 & 24.2 & 0.295 \\
Peers and social support & 74.6 & 18.9 & 70.1 & 21.5 & 0.356 \\
School environment & 64.3 & 18.4 & 56.2 & 22.9 & 0.002 \\
Social acceptance (bullying) & 92.2 & 13.7 & 85.0 & 22.8 & 0.002 \\
Financial resources & 69.9 & 24.4 & 67.9 & 24.5 & 0.508 \\
\hline
\end{tabular}

${ }^{a}$ Multivariate analysis of variance (MANOVA).
The internal consistency reliability of the KIDSCREEN scales can be considered satisfactory with a Cronbach $\alpha$ coefficient of 0.73 or above for all dimensions. The internal consistency is similar to that reported from other studies referring to the reliability of KIDSCREEN [8-11].

There has been an increasing use of CFA for the exploration of psychometric properties of QoL questionnaires during recent years [24]. In the present study CFA confirmed the construct validity of the ten-dimensional measurement model a result consistent with other studies $[8,10,11]$. The RMSEA value was less than 0.05 and the CFI and GFI values were more than 0.95 . The $\chi^{2}$ test of the model was significant, but this can be explained since $\chi^{2}$ statistics are sensitive to large sample sizes [22].

The convergent and discriminant validity analysis indicated that the KIDSCREEN-52 model showed a reasonable pattern of associations. With respect to the relationships between the generic HRQoL dimensions of the KIDSCREEN-52 and the mainly psychologicallyoriented SDQ scales, it can be said that correlations between the two instruments were as predicted. The most significant correlations emerged in general between scales and dimensions tapping similar aspects of behavioral and emotional problems. For example, the correlation between the KIDSCREEN-52 moods and emotions dimension with SDQ emotional symptoms was -0.58 and the correlation between KIDSCREEN-52 peers and social support with SDQ peer problems was -0.40. Additionally, lower correlations between non-comparable scales support the construct validity in the form of discriminant validity (that is, low correlations were found between financial resources and SDQ scales).

High versus low FAS significantly differentiated adolescents in terms of all KIDSCREEN-52 dimensions except for autonomy and social acceptance (bullying). 
Previous studies have generally shown that HRQoL instruments are capable of discriminating between children and adolescents with different socioeconomic status [25].

The KIDSCREEN-52 questionnaire discriminated well in the hypothesized dimension of physical well-being between healthy adolescents and those with chronic physical or mental health problems. Also, differences in psychological well-being, school environment and social acceptance (bullying) were found between healthy adolescents and those with chronic health problems, but no differences between the aforementioned groups were found in the rest of the KIDSCREEN-52 dimensions. More research using the KIDSCREEN-52 questionnaire in clinical conditions is required in order to identify response patterns associated with those conditions.

\section{Strengths and limitations}

The main strength of this study is its large and representative sample size. Also, the strength of our findings is that they are based on several goodness of fit criteria and associations of the measurement model.

However, there are several limitations to this study. Firstly, the identification of the group with chronic health problems was performed with a screening instrument, and no clinical information was available for physical and mental health problems. Thus, future studies should be provided in groups so that the severity of clinical conditions will be available.

Furthermore, because of the cross-sectional design of the study it was not possible to test the sensitivity of the KIDSCREEN-52 instrument to change. Changes over time should be evaluated with a longitudinal study design in future research. Pilot test in Spanish adolescents [26] has shown that KIDSCREEN follow up instrumentation seems adequate for collecting factors with potential influence on HRQoL.

\section{Conclusions}

The results of the present study provide evidence that the KIDSCREEN-52 questionnaire seems to be a reliable and valid instrument for measuring HRQoL in Greek adolescents. The KIDSCREEN-52 questionnaire gives information for ten different aspects of HRQoL and it is also available in two shorter versions (the KIDSCREEN27 index and KIDSCREEN-10 index) [27-29] and as proxy version for parents [30]. The KIDSCREEN questionnaire has been used in previous studies for clinical samples with obesity [31,32], cerebral palsy [33] and cancer [34]. Further research with different clinical samples should be conducted with appropriate cut-off points of HRQoL dimensions differentiating clinical from healthy samples. Measurement of HRQoL in adolescents could be useful in identifying populations at risk and provide targets for intervention in terms of public health.

\section{Acknowledgements}

The KIDSCREEN project was financed by a grant from the European Commission (QLG-CT-2000-00751) within the EC 5th Framework-Programme 'Quality of Life and Management of Living Resources'. This research has been cofinanced by the European Union (European Social Fund (ESF)) and Greek national funds through the Operational Program 'Education and Lifelong Learning' of the National Strategic Reference Framework (NSRF) Research Funding Program: Heracleitus II. Investing in knowledge society through the European Social Fund.

\section{Author details}

${ }^{1}$ Centre for Health Services Research, Department of Hygiene, Epidemiology and Medical Statistics, Athens University Medical School, Athens, Greece. ${ }^{2}$ Department of Hygiene, Epidemiology and Medical Statistics, Athens University Medical School, Athens, Greece. ${ }^{3}$ Department of Psychiatry, Athens University Medical School, Athens, Greece. ${ }^{4}$ Robert Koch Institute, Child and Adolescent Health, Berlin, Germany.

\section{Authors' contributions}

$C T, A T, I Z$ and $C D$ participated in the preparation of the paper. UR-S coordinated the European project 'Screening and Promotion for HRQOL in Children and Adolescents - A European Public Health Perspective'. YT had responsibility for overall supervision of the study. All authors read and approved the final manuscript.

\section{Competing interests}

The authors declare that they have no competing interests.

Received: 29 December 2011 Accepted: 13 February 2012 Published: 13 February 2012

\section{References}

1. The WHOQOL Group: The World Health Organization Quality of Life assessment (WHOQOL): Position paper from the World Health Organization. Soc Sci Med 1995, 41:1403-1409.

2. McHorney CA: Generic health measurement: past accomplishments and a measurement paradigm for the 21st century. Ann Intern Med 1997, 127:743-750.

3. Eiser $C$, Morse $R$ : A review of measures of quality of life for children with chronic illness. Arch Dis Child 2001, 84:205-211.

4. Ravens-Sieberer U, Gosch A, Rajmil L, Erhart M, Bruil J, Duer W, Auquier P, Power M, Abel T, Czemy L, Mazur J, Czimbalmos A, Tountas Y, Hagquist C, Kilroe J, Kidscreen Group E: KIDSCREEN-52 quality-of-life measure for children and adolescents. Expert Rev Pharmacoecon Outcomes Res 2005, 5:353-364.

5. Riley AW: Evidence that school-age children can self-report on their health. Ambul Pediatr 2004, 4(Suppl):371-376.

6. Commitee on evaluation of Children's Health NRC: Measuring Children's Health. Children's Health the Nation's Wealth: Assessing and Improving Child Health Washington, DC: The National Academic Press; 2004.

7. Berra S, Ravens-Sieberer U, Erhart M, Tebe C, Bisegger C, Duer W, von Rueden U, Herdman M, Alonso J, Rajmil L: Methods and representativeness of a European survey in children and adolescents: the KIDSCREEN study. BMC Public Health 2007, 7:182.

8. Haraldstad K, Christophersen KA, Eide H, Nativg GK, Helseth S: Health related quality of life in children and adolescents: reliability and validity of the Norwegian version of KIDSCREEN-52 questionnaire, a cross sectional study. Int J Nurs Stud 2010, 48:573-581.

9. Hong SD, Yang JW, Jang WS, Byun H, Lee MS, Kim HS, Oh MY, Kim JH: The KIDSCREEN-52 quality of life measure for children and adolescents (KIDSCREEN-52-HRQOL): reliability and validity of the Korean version. J Korean Med Sci 2007, 22:446-452.

10. Ravens-Sieberer U, Gosch A, Rajmil L, Erhart M, Bruil J, Power M, Duer W, Auquier P, Cloetta B, Czemy L, Mazur J, Czimbalmos A, Tountas Y, Hagquist C, Kilroe J, KIDSCREEN Group: The KIDSCREEN-52 quality of life measure for children and adolescents: psychometric results from a 
cross-cultural survey in 13 European countries. Value Health 2008, 11:645-658.

11. Tebe C, Berra S, Herdman M, Aymerich M, Alonso J, Rajmil L: Reliability and validity of the Spanish version of the KIDSCREEN-52 for child and adolescent population [in Spanish]. Med Clin (Barc) 2008, 130:650-654.

12. Goodman R: The Strengths and Difficulties Questionnaire: a research note. J Child Psychol Psychiatry 1997, 38:581-586.

13. Rajmil L, Berra S, Rueden U, Tebe C, Erhart M, Gosch A: Representativity of 12 national surveys of children and adolescents 8-18 years old included in the KIDSCREEN HRQoL study. Qual Life Res 2004, 13:1576.

14. The WHOQOL Group: Study protocol for the World Health Organization project to develop a Quality of Life assessment instrument (WHOQOL). Qual Life Res 1993, 2:153-159.

15. Bullinger $\mathrm{M}$, Alonso J, Apolone $\mathrm{G}$, Leplège $\mathrm{A}$, Sullivan $\mathrm{M}$, WoodDauphinee S, Gandek B, Wagner A, Aaronson N, Bech P, Fukuhara S, Kaasa S, Ware JE Jr: Translating health status questionnaires and evaluating their quality: the IQOLA Project approach. International Quality of Life Assessment. J Clin Epidemiol 1998, 51:913-923.

16. Giannakopoulos G, Tzavara C, Dimitrakaki C, Kolaitis G, Rotsika V, Tountas Y: The factor structure of the Strengths and Difficulties Questionnaire (SDQ) in Greek adolescents. Ann Gen Psychiatry 2009, 8:20.

17. Currie CE, Elton RA, Todd J, Platt S: Indicators of socioeconomic status for adolescents: the WHO Health Behaviour in School-aged Children Survey. Health Educ Res 1997, 12:385-397.

18. Ravens-Sieberer U, Torsheim T, Hetland J, Vollebergh W, Cavallo F, Jericek H, Alikasifoglu M, Valimaa R, Ottova V, Erhart M: Subjective health, symptom load and quality of life of children and adolescents in Europe. Int J Public Health 2009, 54(Suppl 2):151-159.

19. Torsheim T, Currie C, Boyce W, Samdal O: Country material distribution and adolescents' perceived health: multilevel study of adolescents in 27 countries. J Epidemiol Community Health 2006, 60:156-161.

20. Bethell CD, Read D, Neff J, Blumberg SJ, Stein RE, Sharp V, Newacheck PW: Comparison of the children with special health care needs screener to the questionnaire for identifying children with chronic conditionsrevised. Ambul Pediatr 2002, 2:49-57.

21. Bethell CD, Read D, Stein RE, Blumberg SJ, Wells N, Newacheck PW: Identifying children with special health care needs: development and evaluation of a short screening instrument. Ambul Pediatr 2002, 2:38-48.

22. Mueller R: Basic Principles of Structural Equation Modeling New York, USA: Springer; 2000.

23. Hu L, Bentler P: Cutoff criteria for fit indices in covariance structure analysis: conventional criteria versus new alternatives. Struct Equ Modeling 1999, 6:1-55.

24. Fayers P, Machin D: Quality of Life. The Assessment, Analysis and Interpretation of Patient-Reported Outcomes. 2 edition. London, UK: Wiley \& Sons Ltd; 2007.

25. Starfield B, Riley AW, Witt WP, Robertson J: Social class gradients in health during adolescence. J Epidemiol Community Health 2002, 56:354-361.

26. Palacio-Vieira JA, Villalonga-Olives E, Alonso J, Valderas JM, Herdman M, Espallargues M, Berra S, Rajmil L: Brief report: The KIDSCREEN follow-up study on Health-related Quality of Life (HRQoL) in Spanish children and adolescents. Pilot test and representativeness. J Adolesc 2010, 33:227-231.

27. Ravens-Sieberer U, Auquier P, Erhart M, Gosch A, Rajmil L, Bruil J, Power M, Duer W, Cloetta B, Czemy L, Mazur J, Czimbalmos A, Tountas Y, Hagquist C, Kilroe J, European KIDSCREEN Group: The KIDSCREEN-27 quality of life measure for children and adolescents: psychometric results from a cross-cultural survey in 13 European countries. Qual Life Res 2007, 16:1347-1356.

28. Ravens-Sieberer U, Erhart M, Rajmil L, Herdman M, Auquier P, Bruil J, Power M, Duer W, Abel T, Czemy L, Mazur J, Czimbalmos A, Tountas $Y$, Hagquist C, Kilroe J, European KIDSCREEN Group: Reliability, construct and criterion validity of the KIDSCREEN-10 score: a short measure for children and adolescents' well-being and health-related quality of life. Qual Life Res 2010, 19:1487-1500.

29. Robitail S, Ravens-Sieberer U, Simeoni MC, Rajmil L, Bruil J, Power M, Duer W, Cloetta B, Czemy L, Mazur J, Czimbalmos A, Tountas Y, Hagquist C, Kilroe J, Auquier P, KIDSCREEN Group: Testing the structural and crosscultural validity of the KIDSCREEN-27 quality of life questionnaire. Qual Life Res 2007, 16:1335-1345.
30. Robitail S, Simeoni MC, Ravens-Sieberer U, Bruil J, Auquier P: Children proxies' quality-of-life agreement depended on the country using the European KIDSCREEN-52 questionnaire. J Clin Epidemiol 2007, 60:469-478.

31. Ottova V, Erhart M, Rajmil L, Dettenborn-Betz L, Ravens-Sieberer U: Overweight and its impact on the health-related quality of life in children and adolescents: results from the European KIDSCREEN survey. Qual Life Res 2012, 21:59-69.

32. Wille N, Bullinger M, Holl R, Hoffmeister U, Mann R, Goldapp C, Reinehr T, Westenhofer J, Egmond-Froehlich A, Ravens-Sieberer U: Health-related quality of life in overweight and obese youths: results of a multicenter study. Health Qual Life Outcomes 2010, 8:36.

33. Arnaud C, White-Koning M, Michelsen SI, Parkes J, Parkinson K, Thyen U, Beckung E, Dickinson HO, Fauconnier J, Marcelli M, McManus V, Colver A: Parent-reported quality of life of children with cerebral palsy in Europe. Pediatrics 2008, 121:54-64.

34. van Dijk J, Huisman J, Moll AC, Schouten-van Meeteren AY, Bezemer PD, Ringens PJ, Cohen-Kettenis PT, Imhof SM: Health-related quality of life of child and adolescent retinoblastoma survivors in the Netherlands. Health Qual Life Outcomes 2007, 5:65.

doi:10.1186/1744-859X-11-3

Cite this article as: Tzavara et al:: Reliability and validity of the KIDSCREEN-52 health-related quality of life questionnaire in a Greek adolescent population. Annals of General Psychiatry 2012 11:3.

\section{Submit your next manuscript to BioMed Central and take full advantage of:}

- Convenient online submission

- Thorough peer review

- No space constraints or color figure charges

- Immediate publication on acceptance

- Inclusion in PubMed, CAS, Scopus and Google Scholar

- Research which is freely available for redistribution

Submit your manuscript at www.biomedcentral.com/submit
Biomed Central 